\title{
Desensitization to carboplatin in low-grade glioma. A revision of 100 treatments in children
}

To the Editor,

Hypersensitivity reactions (HSR) in children during chemotherapy have been increasingly documented. ${ }^{1}$

Rapid drug desensitization (RDD) is practically unknown to most oncologists despite allowing patients to be treated with first-line agents. In pediatric age, there is a lack of guidelines and general principles have been adapted from adults (Figure 1).

Carboplatin is used for the treatment of a wide range of tumors, and the combination with vincristine is the most widely adopted scheme for childhood low-grade glioma (LGG). ${ }^{2}$

The aim of this letter is to report a 10 -year period of experience with RDD to carboplatin in children diagnosed with LGG in a tertiary hospital.

Clinical records of children submitted to RDD to carboplatin between July 2009 and April 2019 were reviewed.

Skin prick tests $(10 \mathrm{mg} / \mathrm{mL}$ ) and intradermal tests ( 1 and $10 \mathrm{mg} /$ $\mathrm{mL}$ ) with carboplatin were performed according to international recommendations. ${ }^{3}$ To minimize pain, a prilocaine-lidocaine patch (EMLA®) was applied 30-60 minutes before.

In all cases, the decision to proceed to RDD was based on a strong clinical suspicion of HSR plus the absence of an equally safe and effective alternative treatment.

In all cases, the family was informed about the risk-benefits of this procedure. Motivation and ability to collaborate were assessed. It should be noted that in no case, the lack of family support restrained the protocol; hospital settings and therapeutic schedule were adapted in case of family limitations.

All patients were desensitized under close supervision of allergists. In milder cases, RDDs were performed in the pediatric oncology day hospital/pediatric ward. In cases of anaphylaxis, the first RDD was performed in the intensive care unit. In the absence of breakthrough reactions (BR), subsequent treatments were moved to usual facilities.

Until 2011, an adapted Cofino-Cohen protocol was applied; ${ }^{4}$ subsequently, the protocol developed by Castells ${ }^{3}$ was used.

Protocols were designed according to the intended cumulative dose and severity of the IR ("tailor-made"). A 12-step protocol with 3 parental preparations with progressive concentrations at incremental rates was initially performed. The usual protocol included premedication with antihistamine and methylprednisolone $(1 \mathrm{mg} / \mathrm{kg}$ ) 1 hour before the infusion, intravenous hydration, and ondansetron.
If needed, adaptations of the initial protocol, including the addition of several intermediate steps and even of a fourth bag, were performed as well as a pre-medication reinforcement.

A total of 48 patients received intravenous carboplatin for LGG, and 15 had a reaction compatible with an IgE-mediated HSR (incidence of $31 \%$ ).

All were being treated with carboplatin $\left(550 \mathrm{mg} / \mathrm{m}^{2}\right)$ plus vincristine. The median age at the IR was 3 years old (range, 18 months-9 years old) (Table 1). A median of 8 cycles of carboplatin was performed until the IR, the majority starting $<30$ minutes after infusion (all within $1 \mathrm{~h}$ ). The clinical pattern varied from moderate (isolated mucocutaneous symptoms in 6 cases) to severe (9 anaphylactic reactions). Acute and baseline tryptase was measured in only 5 of 9 patients with anaphylaxis and was elevated (baseline tryptase $\times 1.2+2 \mathrm{ng} / \mathrm{ml}$ ) in 3 . Only one patient received epinephrine.

Skin tests (ST) were negative in the 4 tested patients.

No schedule delays due to desensitizations procedures occurred.

In total, 100 RDDs to carboplatin were performed with a median of 6.7 treatments per patient. In 6 patients, RDDs were successful in the first treatment, and in 9 patients (60\%), adaptations to the initial protocol and reinforcement of pre-medication were performed (antihistamines, corticosteroids, and montelukast). The BR were more severe than the initial reaction in 4 patients.

In the majority of cases (78\%), BR were successfully managed by discontinuing the infusion and administering rescue medication; the infusion was only restarted once the symptoms resolved.

In 2 patients, the RDDs were unsuccessful due to severe BR despite adaptations and an alternative drug was used.

\section{DISCUSSION}

Literature data on carboplatin HSR in children with LGG are limited. The higher rate of HSR was found in the cohort of Dudgshun et $\mathrm{al}^{5}$ and the frequency differed according to the protocol used; $8 \%$ of patients treated with only carboplatin and $68 \%$ of those with combined carboplatin and vincristine presented HSR, respectively. An immune potentiating effect of the association of the drugs was hypothesized. In our study, all patients were treated with carboplatin and vincristine but our rate of HSR was significantly lower. Our study did not 
Main protocol for $\mathbf{4 0 7} \mathrm{mg}$ carboplatin desensitization

\begin{tabular}{|l|l|l|l|}
\hline Solution & Total Volume & Concentration & Dose \\
\hline Solution A & $250 \mathrm{~mL}$ & $0.02 \mathrm{mg} / \mathrm{mL}$ & $5 \mathrm{mg}$ \\
\hline Solution B & $250 \mathrm{~mL}$ & $0.2 \mathrm{mg} / \mathrm{mL}$ & $50 \mathrm{mg}$ \\
\hline Solution C & $250 \mathrm{~mL}$ & $2 \mathrm{mg} / \mathrm{mL}$ & $500 \mathrm{mg}$ \\
\hline
\end{tabular}

\begin{tabular}{|c|c|c|c|c|c|c|}
\hline Step & Solution & $\begin{array}{c}\text { Rate } \\
(\mathbf{m l} / \mathbf{h})\end{array}$ & $\begin{array}{c}\text { Time } \\
(\mathbf{m i n})\end{array}$ & $\begin{array}{c}\text { Volume } \\
(\mathbf{m L})\end{array}$ & $\begin{array}{c}\text { Dose } \\
(\mathbf{m g})\end{array}$ & $\begin{array}{c}\text { Cumulative } \\
\text { Dose (mg) }\end{array}$ \\
\hline $\mathbf{1}$ & $\mathrm{A}$ & 2 & 15 & 0.5 & 0.01 & 0.01 \\
\hline $\mathbf{2}$ & $\mathrm{A}$ & 5 & 15 & 1.25 & 0.025 & 0.035 \\
\hline $\mathbf{3}$ & $\mathrm{A}$ & 10 & 15 & 2.5 & 0.05 & 0.085 \\
\hline $\mathbf{4}$ & $\mathrm{A}$ & 20 & 15 & 5 & 0.1 & 0.185 \\
\hline $\mathbf{5}$ & $\mathrm{B}$ & 5 & 15 & 1.25 & 0.25 & 0.435 \\
\hline $\mathbf{6}$ & $\mathrm{B}$ & 10 & 15 & 2.5 & 0.5 & 0.935 \\
\hline $\mathbf{7}$ & $\mathrm{B}$ & 20 & 15 & 5 & 1 & 1.935 \\
\hline $\mathbf{8}$ & $\mathrm{B}$ & 40 & 15 & 10 & 2 & 3.935 \\
\hline $\mathbf{9}$ & $\mathrm{C}$ & 10 & 15 & 2.5 & 5 & 8.935 \\
\hline $\mathbf{1 0}$ & $\mathrm{C}$ & 20 & 15 & 5 & 10 & 18.935 \\
\hline $\mathbf{1 1}$ & $\mathrm{C}$ & 40 & 15 & 10 & 20 & 38.935 \\
\hline $\mathbf{1 2}$ & $\mathrm{C}$ & 80 & 145 & 193.5 & 387 & 407 \\
\hline
\end{tabular}

Scenario 1. Recurrent generalized urticaria at the $9^{\mathrm{h}}$ step requiring antihistamines and corticosteroids.

An additional step was added

\begin{tabular}{|l|l|l|l|}
\hline Solution & Total Volume & Concentration & Dose \\
\hline Solution A & $250 \mathrm{~mL}$ & $0.02 \mathrm{mg} / \mathrm{mL}$ & $5 \mathrm{mg}$ \\
\hline Solution B & $250 \mathrm{~mL}$ & $0.2 \mathrm{mg} / \mathrm{mL}$ & $50 \mathrm{mg}$ \\
\hline Solution C & $250 \mathrm{~mL}$ & $2 \mathrm{mg} / \mathrm{mL}$ & $500 \mathrm{mg}$ \\
\hline
\end{tabular}

\begin{tabular}{|c|c|c|c|c|c|c|}
\hline Step & Solution & $\begin{array}{c}\text { Rate } \\
(\mathbf{m l} / \mathbf{h})\end{array}$ & $\begin{array}{c}\text { Time } \\
(\mathbf{m i n})\end{array}$ & $\begin{array}{c}\text { Volume } \\
(\mathbf{m L})\end{array}$ & $\begin{array}{c}\text { Dose } \\
(\mathbf{m g})\end{array}$ & $\begin{array}{c}\text { Cumulative } \\
\text { Dose }(\mathbf{m g})\end{array}$ \\
\hline $\mathbf{1}$ & $\mathrm{A}$ & 2 & 15 & 0.5 & 0.01 & 0.01 \\
\hline $\mathbf{2}$ & $\mathrm{A}$ & 5 & 15 & 1.25 & 0.025 & 0.035 \\
\hline $\mathbf{3}$ & $\mathrm{A}$ & 10 & 15 & 2.5 & 0.05 & 0.085 \\
\hline $\mathbf{4}$ & $\mathrm{A}$ & 20 & 15 & 5 & 0.1 & 0.185 \\
\hline $\mathbf{5}$ & $\mathrm{B}$ & 5 & 15 & 1.25 & 0.25 & 0.435 \\
\hline $\mathbf{6}$ & $\mathrm{B}$ & 10 & 15 & 2.5 & 0.5 & 0.935 \\
\hline $\mathbf{7}$ & $\mathrm{B}$ & 20 & 15 & 5 & 1 & 1.935 \\
\hline $\mathbf{8}$ & $\mathrm{B}$ & 40 & 15 & 10 & 2 & 3.935 \\
\hline $\mathbf{9}$ & $\mathrm{C}$ & 5 & 15 & 1.25 & 2.5 & 6.435 \\
\hline $\mathbf{1 0}$ & $\mathrm{C}$ & 10 & 15 & 2.5 & 5 & 11.435 \\
\hline $\mathbf{1 1}$ & $\mathrm{C}$ & 20 & 15 & 5 & 10 & 21.435 \\
\hline $\mathbf{1 2}$ & $\mathrm{C}$ & 40 & 15 & 10 & 20 & 41.435 \\
\hline $\mathbf{1 3}$ & $\mathrm{C}$ & 80 & 137 & 182.8 & 365.6 & 407 \\
\hline
\end{tabular}

Scenario 2. Anaphylaxis at the $3^{\text {rd }}$ step. An additional bag was added.

\begin{tabular}{|l|l|l|l|}
\hline Solution & Total Volume & Concentration & Dose \\
\hline Solution A & $250 \mathrm{~mL}$ & $0.002 \mathrm{mg} / \mathrm{mL}$ & $0.5 \mathrm{mg}$ \\
\hline Solution B & $250 \mathrm{~mL}$ & $0.02 \mathrm{mg} / \mathrm{mL}$ & $5 \mathrm{mg}$ \\
\hline Solution C & $250 \mathrm{~mL}$ & $0.2 \mathrm{mg} / \mathrm{mL}$ & $50 \mathrm{mg}$ \\
\hline Solution D & $250 \mathrm{~mL}$ & $2 \mathrm{mg} / \mathrm{mL}$ & $500 \mathrm{mg}$ \\
\hline
\end{tabular}

\begin{tabular}{|c|c|c|c|c|c|c|}
\hline Step & Solution & $\begin{array}{c}\text { Rate } \\
(\mathbf{m l} / \mathbf{h})\end{array}$ & $\begin{array}{c}\text { Time } \\
(\mathbf{m i n})\end{array}$ & $\begin{array}{c}\text { Volume } \\
(\mathbf{m L})\end{array}$ & $\begin{array}{c}\text { Dose } \\
(\mathbf{m g})\end{array}$ & $\begin{array}{c}\text { Cumulative } \\
\text { Dose }(\mathbf{m g})\end{array}$ \\
\hline $\mathbf{1}$ & $\mathrm{A}$ & 2 & 15 & 0,5 & 0,001 & 0.001 \\
\hline $\mathbf{2}$ & $\mathrm{A}$ & 5 & 15 & 1,25 & 0.0025 & 0.0035 \\
\hline $\mathbf{3}$ & $\mathrm{A}$ & 10 & 15 & 2,5 & 0.005 & 0.0085 \\
\hline $\mathbf{4}$ & $\mathrm{A}$ & 20 & 15 & 5 & 0.01 & 0.0185 \\
\hline $\mathbf{5}$ & $\mathrm{B}$ & 5 & 15 & 1,25 & 0.025 & 0.0435 \\
\hline $\mathbf{6}$ & $\mathrm{B}$ & 10 & 15 & 2,5 & 0.05 & 0.0935 \\
\hline $\mathbf{7}$ & $\mathrm{B}$ & 20 & 15 & 5 & 0.1 & 0.1935 \\
\hline $\mathbf{8}$ & $\mathrm{B}$ & 40 & 15 & 10 & 0.2 & 0.3935 \\
\hline $\mathbf{9}$ & $\mathrm{C}$ & 10 & 15 & 2,5 & 0.5 & 0.8935 \\
\hline $\mathbf{1 0}$ & $\mathrm{C}$ & 20 & 15 & 5 & 1 & 1.8935 \\
\hline $\mathbf{1 1}$ & $\mathrm{C}$ & 40 & 15 & 10 & 2 & 3.8935 \\
\hline $\mathbf{1 2}$ & $\mathrm{C}$ & 80 & 15 & 20 & 4 & 7.8935 \\
\hline $\mathbf{1 3}$ & $\mathrm{D}$ & 20 & 15 & 5 & 10 & 17.8935 \\
\hline $\mathbf{1 4}$ & $\mathrm{D}$ & 40 & 15 & 10 & 20 & 37.8935 \\
\hline $\mathbf{1 5}$ & $\mathrm{D}$ & 80 & 15 & 20 & 40 & 77.8935 \\
\hline $\mathbf{1 6}$ & $\mathrm{D}$ & 100 & 99 & 164,6 & 329,1 & 407 \\
\hline
\end{tabular}

FIGURE 1 For understanding purpose, an adapted protocol was adjusted according to 2 hypothetical scenarios, based on our patients

include patients that tolerated subsequent infusions after preventive measures were started, and this may explain the results' difference as only one-third of Dodgshun's patients were desensitized with carboplatin.

In accordance with previous studies, the reactions begun at the eighth cycle; the risk of hypersensitivity to carboplatin seems to be related to the cumulative number of exposures rather than to the cumulative dose itself. ${ }^{1,3,6,7}$

Anaphylaxis represented $60 \%$ of the IR, in agreement with the literature which reports that most of platinum HSR are severe. ${ }^{8}$

Only one patient was treated with adrenaline, which emphasizes the worldwide reality in which anaphylaxis is often under recognized and under-treated. ${ }^{\text {? }}$
ST to carboplatin have been recommended between the fifth and eighth cycle in order to predict the risk of future HSR. ${ }^{10}$ However, the implications of a positive test are not clear, especially in children. The young age and the fragility of these patients also justified skipping this prophylactic ST in our children.

Diagnostic ST to carboplatin were not performed in every patient as the optimal timing could imply a treatment delay. Of the 4 patients tested, none had positive ST. Non-irritative concentrations are only validated in adults and children may behave differently and display positive results less frequently or with different concentrations. ${ }^{11}$ Validation of ST with EMLA ${ }^{\circledR}$ with other drugs found no differences in ST results but platins were not evaluated in this study. ${ }^{12}$ 

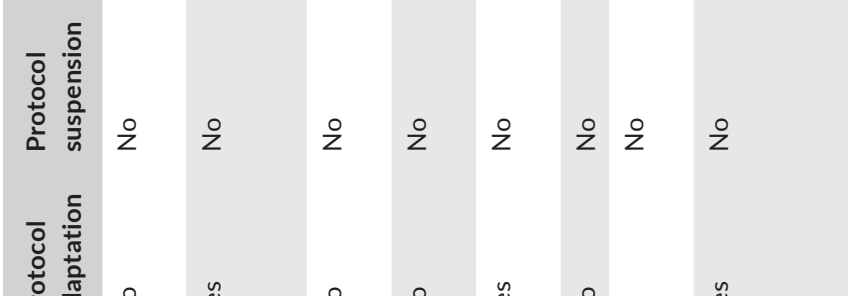

은 $\frac{\pi}{\pi}$
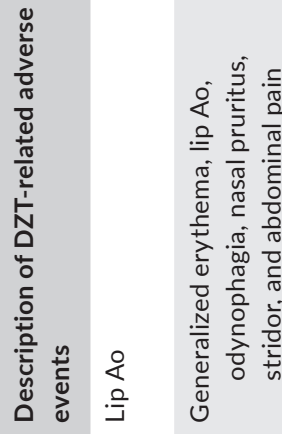

$\stackrel{\square}{\rightleftharpoons}$

요요

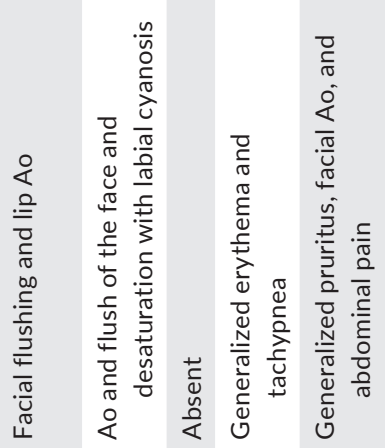

ํํำ

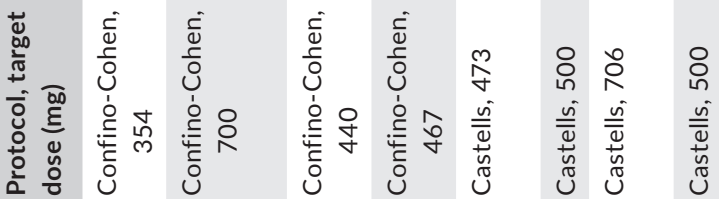

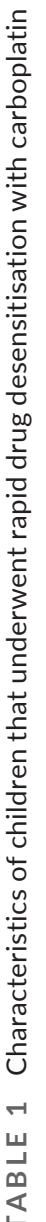

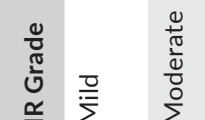

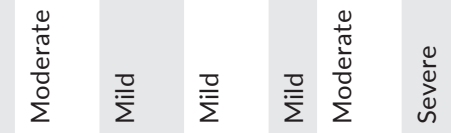

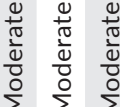

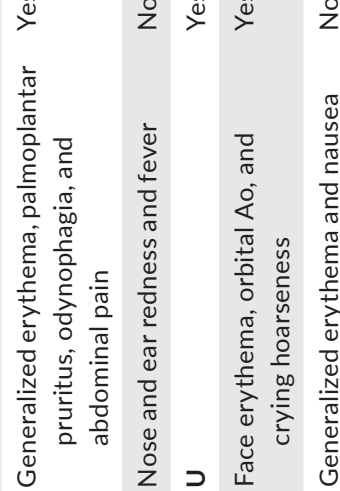

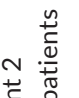

永

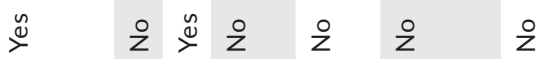
등

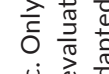

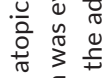
등ㅇ

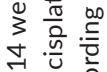

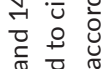
국

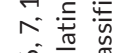
응

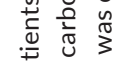

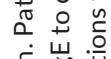

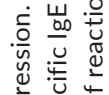

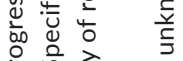
咅设

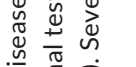

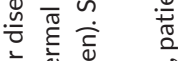

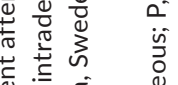

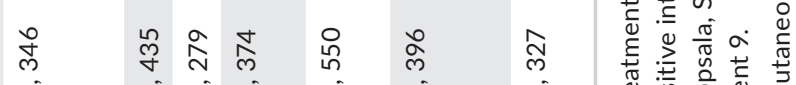

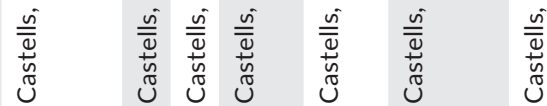

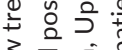
उ.

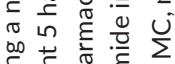

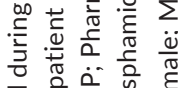

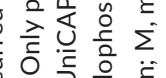
पू.

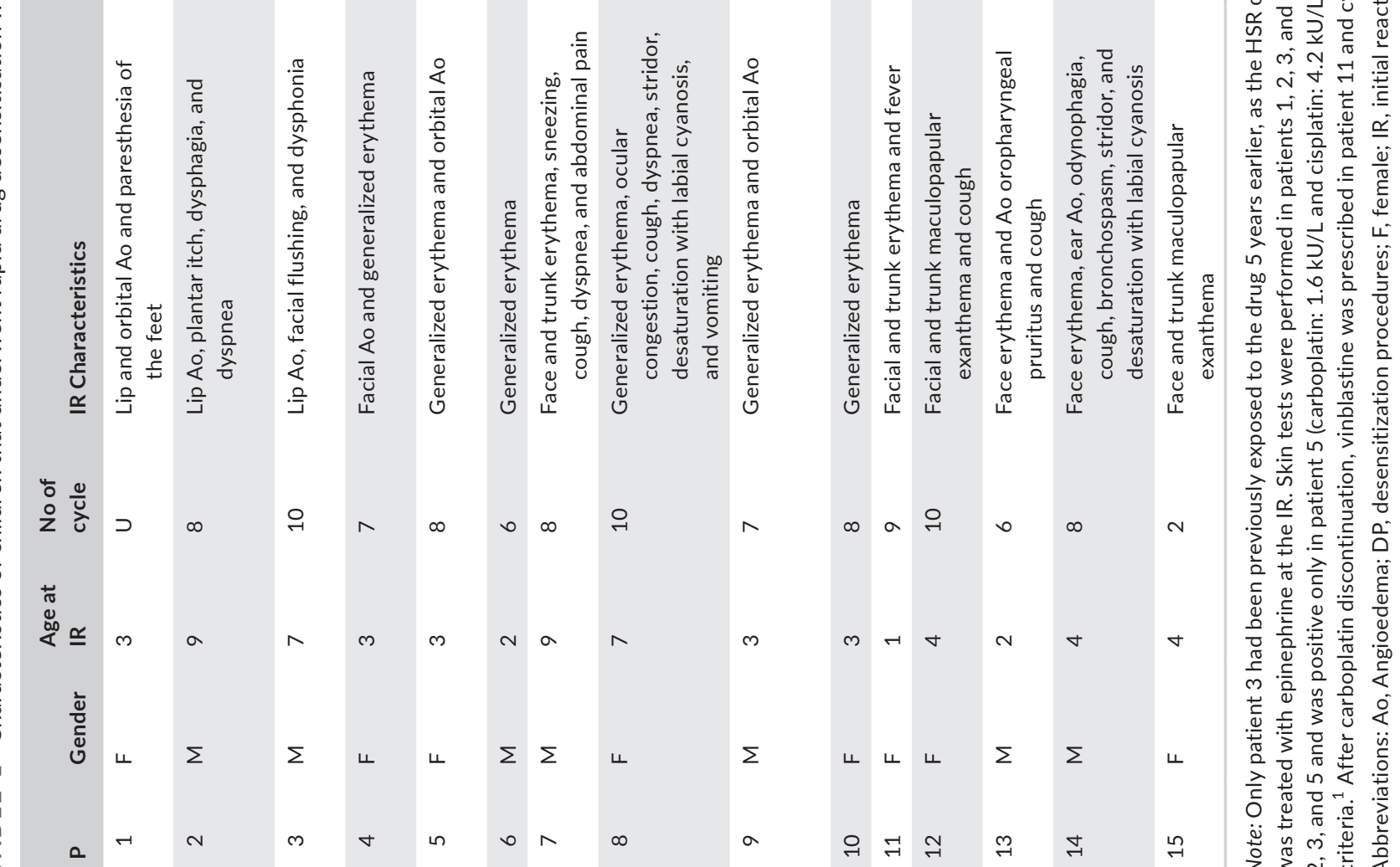


Although none of the suspected HSR was confirmed by ST, the high rate of BR during RDD (60\%) corroborates the initial diagnosis.

Only 2 patients (13\%) failed RDD. They had bothersome symptoms that persisted or even worsen with RDD despite several modifications to the initial protocol.

BR during RDD were more severe than the IR in 4 cases; a more accurate characterization of the reactions by allergists might be an explanation.

The success rate of RDD to carboplatin in this study was $87 \%$, comparable to rates ${ }^{3}$ in adult series, but significantly different from some of pediatric series with higher success rates observed in milder reactions or lower carboplatin doses. ${ }^{1,5-7,11}$

The SIOP guidelines ${ }^{2}$ discourages RDD to carboplatin; nevertheless, RDD has been successfully performed in our department as in several other centers. ${ }^{4,6,7,11}$ However, the high rate of severe reactions during RDD highlights the importance of such procedures to take place under the supervision of an allergist, in a pediatric oncology center.

RDD was performed even in infants that achieved several years of survival after treatment. Two patients (4 and 5) died after treatment conclusion due to disease progression.

Limitations of the study include the small number of patients and the absence of all data in some patients due to its retrospective nature.

In conclusion, clinicians must not underestimate the potential risk of HSR to chemotherapy in children. However, RDDs performed under suitable conditions can be an option for these patients, improving the final oncologic outcome. To our knowledge, this is the biggest case series on desensitization to carboplatin in children.

\section{CONFLICT OF INTEREST}

The authors declare no conflicts of interest.

\section{AUTHOR CONTRIBUTIONS}

Leonor Carneiro-Leão: Visualization (equal); Writing-review \& editing (equal).

\section{ETHICAL STATEMENT}

The study conforms to the ethical principles contained in the Declaration of Helsinki.

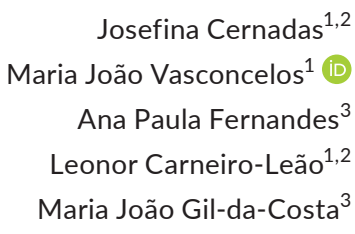

${ }^{1}$ Serviço de Imunoalergologia, Centro Hospitalar Universitário de São João, Porto, Portugal
${ }^{2}$ Unidade de Imunoalergologia, Hospital dos Lusíadas, Porto,

Portugal

${ }^{3}$ Serviço de Oncologia Pediátrica, Centro Hospitalar Universitário de São João, Porto, Portugal

Correspondence

Maria João Vasconcelos, Serviço de Imunoalergologia, Centro Hospitalar Universitário de São João, Porto, Portugal. Email: mariajoaosvasconcelos@gmail.com

Editor: Marina Atanaskovic-Markovic

Cernadas and Vasconcelos contributed equally to this study

\section{ORCID}

Maria João Vasconcelos (D) https://orcid.org/0000-0002-1176-153X

\section{REFERENCES}

1. Turgay Yagmur I, Guzelkucuk Z, Yarali N, et al. Evaluation of hypersensitivity reactions to cancer chemotherapeutic agents in pediatric patients. Ann Allergy Asthma Immunol. 2020;124(4):350-356.

2. National Cancer Institute. Clinical trial. Available at URL: http:// www.cancer.gov/search/ViewClinicalTrials..aspx?cdrid54545 06\&version5patient\&protocolssearchid53447647. Accessed July 5,2007

3. Castells MC, Tennant NM, Sloane DE, et al. Hypersensitivity reactions to chemotherapy: outcomes and safety of rapid desensitization in 413 cases. J Allergy Clin Immunol. 2008;122(3):574-580.

4. Confino-Cohen R, Fishman A, Altaras M, et al. Successful carboplatin desensitization in patients with proven carboplatin allergy. Cancer. 2005;104(3):640-643.

5. Dodgshun AJ, Hansford JR, Cole T, et al. Carboplatin hypersensitivity reactions in pediatric low grade glioma are protocol specific and desensitization shows poor efficacy. Pediatr Blood Cancer. 2016;63(1): 17-20.

6. Genc DB, Canpolat C, Berrak SG. Clinical features and management of carboplatin-related hypersensitivity reactions in pediatric lowgrade glioma. Support Care Cancer. 2012;20(2):385-393.

7. Shah AC, Minturn JE, Li Y, et al. Carboplatin rechallenge after hypersensitivity reactions in pediatric patients with low-grade glioma. Pediatr Blood Cancer. 2016;63(1):21-26.

8. Pradelli J, Verdoire P, Boutros J, et al. Allergy evaluation of hypersensitivity to platinum salts and taxanes: a six-year experience. $J$ Allergy Clin Immunol Pract. 2020;8(5):1658-1664.

9. Grabenhenrich LB, Dölle S, Ruëff F, et al. Epinephrine in severe allergic reactions: the european anaphylaxis register. J Allergy Clin Immunol Pract. 2018;6(6):1898-1906 e1.

10. Markman M, Zanotti K, Peterson G, et al. Expanded experience with an intradermal skin test to predict for the presence or absence of carboplatin hypersensitivity. J Clin Oncol. 2003;21(24):4611-4614

11. Rodriguez Del Rio P, Andión M, Ruano D, et al. Initial experience with carboplatin desensitization: a case series in a paediatric hospital. Pediatr Allergy Immunol. 2018;29(1):111-115.

12. Couto M, Silva D, Ferreira A, et al. Intradermal tests for diagnosis of drug allergy are not affected by a topical anesthetic patch. Allergy Asthma Immunol Res. 2014;6(5):458-462. 